\title{
A meta-analysis of integrated compression screw compared to single screw nails using a single lag screw or single helical blade screw for intertrochanteric hip fractures
}

\author{
Nherera $\mathrm{LM}^{1 *}$, Trueman $\mathrm{P}^{1}$, Horner $\mathrm{A}^{1}$, Johnstone $\mathrm{AJ}^{2}$ and Watson $\mathrm{JT}^{3}$ \\ ${ }^{1}$ Smith \& Nephew, Hull, UK \\ ${ }^{2}$ Orthopaedic Trauma Unit, Aberdeen Royal Infirmary, Aberdeen, UK \\ ${ }^{3}$ University of AZ College of Medicine -Phoenix Department of Orthopaedic Surgery, The CORE Institute.
}

\begin{abstract}
Background: Surgical treatment is the optimal strategy for managing intertrochanteric fractures as it allows early rehabilitation and functional recovery. We sought to assess the clinical effectiveness of commonly used intramedullary devices for the treatment of unstable intertrochanteric hip fractures and also assess if there was a class effect of these nails.

Methods: A comprehensive systematic literature review and meta-analysis of studies was conducted comparing an Integrated Compression Screw nail (ICS) with conventional single screw nails using a single lag screw (SLS) or a single helical blade (SHB). We assessed the following outcomes, device related complications (shaft fracture, varus collapse and cut-outs), revisions, non-unions, hip and thigh pain, Harris Hip Score, health related quality of life, operating and fluoroscopy time, blood loss and other complications. We report odds ratios for dichotomous outcomes and mean difference for continuous outcomes.

Results: Twelve studies with 1,661 patients were included, 8 comparing ICS with SHB and 4 comparing ICS with SLS. Mean age was 76 years and 71\% of patients were female. There were significant differences $(\mathrm{p}<0.05)$ in device performance in favour of ICS for implant related failures, fewer revisions, hip and thigh pain and better function as measured by SF-36 and HHS compared to single screw nails. Operating time and fluoroscopy time significantly favoured single screw nails. No differences were seen in non-unions, blood loss, and other complications.

Conclusion: Our meta-analysis suggests that there are significant differences between ICS and the single screw nails in favour of ICS with respect to the incidence of implant related failures, revision, functional outcomes and proportion of patients reporting hip and thigh pain. Operating time favours the single screw nails while no differences were observed regarding non-unions, blood loss and other complications. There is no evidence of class effect regarding intrameduallary nails in this patient population.
\end{abstract}

\section{Introduction}

By 2050, the number of hip fractures worldwide is estimated to surpass 6.3 million. In the US alone, the number of hip fractures is estimated to increase from about 320,000 per year, of which around 150,000 are intertrochanteric fractures, to 580,000 by 2040 [1-4]. Furthermore, in the USA it is estimated that hip fractures account for approximately $14 \%$ of all fractures but result in approximately $70 \%$ of the acute care and subsequent hospital care costs associated with fracture treatment [5], with healthcare costs exceeding $\$ 10$ billion per year. This is expected to continue to rise with the corresponding increase in life expectancy $[1,2,6,7]$. A similar trend is observed in the European Union. For instance, in 2010 there were an estimated 600,000 hip fractures costing $€ 20$ billion to the health system [8]. Studies have also suggested an association between hip fracture and mortality, with the 1-year mortality rate for hip fractures ranging from $14 \%$ to $36 \%$, with $30 \%$ more deaths observed than with an age matched population [9-11].

Surgical intervention is the definitive treatment for these fractures as it enables patient early mobilization and subsequent return to acceptable levels of function $[1,5]$. Implant choice is determined by whether the fracture is "stable" or "unstable" which is predominantly dependant on the status of the posteromedial cortex [12]. According to the Orthopaedic Trauma Association (OTA/AO) fracture classification system, type A1 is universally considered stable and type A3 is generally considered unstable, while the stability of A2 fractures are less clear. For this study we considered OTA/AO fracture classification system A2-1 and above as unstable [12].

A number of studies and systematic reviews have been conducted to offer a comprehensive assessment of alternative internal fixation treatments for intertrochanteric fractures [2,11-15]. Most recently [14] reported results of an Intergrated 2-nailing system compared with one nail-system and concluded that ICS was as effective as the control group in terms of Harris Hip Score (HHS), blood loss, total complications,

${ }^{\star}$ Correspondence to: Nherera L, Director Health Economics, Smith \& Nephew Global Market Access, 101 Hessle Road Hull, HU3 2BN, UK, E-mail: leo. nherera@smith-nephew.com

Key words: intramedullary nail, integrated compression screw, single lag screw, single helical blade, intertrochanteric hip fractures, intertan, PFNA, gamma3, meta-analysis

Received: July 27, 2018; Accepted: August 19, 2018; Published: August 23, 2018 
Nherera LM (2018) A meta-analysis of integrated compression screw compared to single screw nails using a single lag screw or single helical blade screw for intertrochanteric hip fractures

union time, length of hospital stay, revision rate, and fluoroscopy time. ICS showed lower rates of implant cut-out and femoral fractures when compared with control groups. This result differed from another recent systematic review by Nherera [13] which found that in addition to improved implant related failure rates, ICS also resulted in lower rates of revision and fewer reports of hip and thigh pain when compared to a single helical blade. This difference in conclusions may be due to additional studies included in Nherera [13] that were not included in the analysis by $\mathrm{Ma}[14]$ analysis.

We therefore sought to update the meta-analysis by Nherera [13] and the one by $\mathrm{Ma}$ [14] and combine all single screw nail studies (SHB and SLS) to comprehensively assess the difference in outcomes and test the hypothesis that there could be a class effect around intramedullary nails in unstable fractures. Our study thus compared ICS nail (TRIGEN $^{\diamond}$ INTERTAN Smith \& Nephew, Memphis, Tennessee) with conventional single screw nails defined as single helical blade (SHB) Proximal Femoral Nail Antirotation (PFNA ${ }^{\text {tw }}$ ) (DePuy Synthes, Solothurn, Switzerland) and single lag screw (SLS) (Gamma3 ${ }^{\text {ma }}$; Stryker, Schönkirchen, Germany) in the treatment of intertrochanteric fractures.

\section{Methods}

\section{Data sources and searches}

We searched for randomised clinical trials (RCTs) and comparative observational studies comparing ICS with single screw nails (SHB, SLS) from January 2000 to May 2018. The following electronic databases were searched, PubMed, Cochrane Database of Systematic Reviews (CDSR), Cochrane Central Register of Controlled Trials (CENTRAL), Health Technology Assessment (HTA) Database, ClinicalTrials. gov. The search terms used included the following "hip fracture, InterTAN, intertrochanteric fractures, integrated compression screw, cepahlomedullary nails, single screw nail, Gamma nail, Gamma 3, PFNA, PFNA-11, single helical blade, single lag screw nails". We also hand-searched references of relevant papers in and recently published systematic reviews $[13,14]$ to ensure completeness.

\section{Study selection and eligibility criteria}

We included RCTs and prospective comparative observational studies with no language restriction if they enrolled participants diagnosed with intertrochanteric fractures; comparing ICS with SLS or SHB. The primary outcome was defined as implant related failures (i.e., cut out, varus collapse, shaft fractures). The secondary outcomes were revisions, non-union, functional measures (i.e. quality of life scores Harris Hip scores and pain), and procedural measures, (i.e. operative time, blood loss, fluoroscopy time). Mortality and length of stay were not included in this analysis because these outcomes are confounded by the patient group i.e., most patients are elderly, frail with multiple comorbidities and therefore the implants are unlikely to have an impact on mortality or length of stay. The inclusion and exclusion criteria are outlined in (Table 1).

\section{Study procedures and data extraction}

Two authors (LN and $\mathrm{AH}$ ) independently screened all titles and abstracts based on the population, intervention, comparators and outcomes (PICO) framework [16] using a pilot-tested data extraction form. The quality of included RCTs was assessed using the Cochrane Collaboration's risk of bias tool [17] and for, observational studies we used the Good Research for Comparative Effectiveness (GRACE) checklist [18]. The following data from eligible studies were extracted;
Table 1. Study inclusion exclusion criteria

\begin{tabular}{|c|c|c|}
\hline Criteria & Inclusion & Exclusion \\
\hline Type of study & $\begin{array}{l}\text { RCTs, prospective } \\
\text { comparative observational } \\
\text { studies }\end{array}$ & $\begin{array}{l}\text { Systematic reviews, } \\
\text { conference abstracts, case } \\
\text { series, case reports, narrative } \\
\text { reviews, editorials, opinions; } \\
\text { studies performed in animals }\end{array}$ \\
\hline Population & $\begin{array}{l}\text { Adults with intertrochanteric } \\
\text { hip fractures }\end{array}$ & Stable fractures alone \\
\hline Geographical location & $\begin{array}{l}\text { Publications from any } \\
\text { country }\end{array}$ & None \\
\hline Interventions & $\begin{array}{l}\text { Integrated compression } \\
\text { screw nail (ICS) (InterTAN) }\end{array}$ & $\begin{array}{l}\text { Other nails other than ICS, } \\
\text { SLS and SHB. }\end{array}$ \\
\hline Comparators & $\begin{array}{l}\text { single lag screw (SLS) i.e, } \\
\text { Gamma } 3 \text { and single helical } \\
\text { blade crew (SHB) i.e, } \\
\text { PFNA, PFNA-11 }\end{array}$ & $\begin{array}{l}\text { Other nails other than } \\
\text { InterTAN and Gamma 3, } \\
\text { PFNA. }\end{array}$ \\
\hline Outcomes of interest & $\begin{array}{l}\text { Post-operative implant } \\
\text { related failures (i.e. cut } \\
\text { out, varus collapse, shaft } \\
\text { fractures) non-union, } \\
\text { revisions, functional } \\
\text { measures (i.e. quality of } \\
\text { life scores and pain, Harris } \\
\text { Hip Score), and procedure } \\
\text { measures (i.e. operative } \\
\text { time, blood loss, fluoroscopy } \\
\text { time), other complications } \\
\text { (deep vein thrombosis, } \\
\text { cardiovascular disorders, } \\
\text { pressure sores, urinary } \\
\text { tract infection, pulmonary } \\
\text { embolism and hematomas) }\end{array}$ & Length of stay, mortality \\
\hline
\end{tabular}

RCT: Randomised Controlled Trial; ICS: Integrated Compression Screw; PFNA: Proximal Femoral Nail Antirotation; SLS: Single Lag Screw; SHB: Single Helical Blade Screw.

study characteristics; (year of publication, simple size, country, length of follow up); patient characteristics (gender, age); intervention/ comparator and the pre-specified outcomes.

\section{Meta-analysis}

Meta-analyses were performed in Review Manager (RevMan), Version 5.3. Copenhagen: The Nordic Cochrane Centre, The Cochrane Collaboration, 2014, using either a fixed-effect or a randomeffect model depending with the presence or absence of significant heterogeneity between studies. For dichotomous outcomes, odds ratio (OR) with a $95 \% \mathrm{CI}$ was reported as the summary statistic. For continuous outcomes, such as HHS, fluoroscopy time, blood loss we used the mean difference (MD). We used the inverse variance and Mantel-Haenszel methods to combine separate statistics and if $p$ values were less than 0.05 , the results were considered statistically significant. Data were analysed separately for SBH and SLS, however, the main analysis reports the results of the combined analysis. This is depature from the analysis that was conducted by $\mathrm{Ma}$ [14] who did not pool the results of the individual single screw intramedullary nails.

\section{Sensitivity analysis}

The main analysis reported the pooled results of SHB and SLS. The analysis shown in the forest plots was done by considering each single screw nail individually. We also used alternative pooling methods (Peto method vs. Mantel-Haenszel method applicable to dichotomous data). Studies that reported follow-up less than 12 months and those that had mixed populations were removed from the analysis to see the impact on the overall conclusions. 
Nherera LM (2018) A meta-analysis of integrated compression screw compared to single screw nails using a single lag screw or single helical blade screw for intertrochanteric hip fractures

\section{Investigation of heterogeneity and assessment of reporting bias}

Heterogeneity of the included studies was assessed using the $I^{2}$ statistic [19]. If the calculated $I^{2}$ statistic was less than $50 \%$, a fixed-effect model was used (no substantial heterogeneity) and when the calculated $I^{2}$ statistic was more than $50 \%$, a random-effects model was used. We used funnel plot to evaluate reporting biases qualitatively, however it is acknowledged that the funnel plot is incapable of identifying which type of bias is present if any [20].

\section{Results}

\section{Literature search}

The initial search found 542 articles and following the removal of duplicates and unrelated articles 25 full articles were assessed for detailed evaluation. After the evaluation of the full titles a further 13 were excluded and therefore 12 studies met the inclusion criteria and were included in the meta-analysis (Figure 1). Of those that met the inclusion criteria, 8 studies compared ICS with SHB [21-28] and 4 compared ICS with SLS [29-32]. Of the 12 studies, five were RCTs, [21,22,29,30,31] and 7 were observational studies, [23-28,32] all published between 2013 and 2018. There were 1661 patients in the 12 studies that met the inclusion criteria, of which 784 were treated with ICS while 877 were treated with single nail screws. The mean age of patients in the studies was 76 years, and $71 \%$ were females. The sample sizes ranged from 56 to 283 , and the length of follow up ranged from 4.6 to 60 months. Four studies recruited both stable and unstable fractures $[21,24,27,29]$ and none explored the effects of devices by fracture type. The majority of the RCTs were rated as having an unclear risk of bias, generally due to a lack of adequate information being reported in the methods according to the Cochrane quality checklist [17] while the observational study was deemed to be of adequate quality according to GRACE checklist [18]. The key characteristics of all included studies are summarised in (Table 2).

\section{Clinical results}

\section{Primary outcome}

Implant related failures: Eleven of the twelve studies reported implant related failure data defined as cut out, varus collapse and shaft fractures [21-23,25-32] ( $\mathrm{n}=1605$ patients); the only study not to report these outcomes was Wang [24]. A total of 764 patients were treated with the ICS and 841 were treated with single screw nails. The combined pooled results showed that ICS significantly reduced the risk of implant related failures by $81 \%$ compared to single screw nails OR: $0.19,95 \%$ CI 0.12 to $0.29, I^{2}=19 \%, \mathrm{p}<0.00001$. The results remained significant when the single nails where considered individually $(85 \%$ reduction $\mathrm{p}<0.00001$ for SHB and $68 \%$ reduction $\mathrm{p}=0.007$ for SLS). The results are shown in (Figure 2).

\section{Secondary outcomes}

Revisions: Nine studies reported data on revisions [21-23, 27-32] $(n=1383$ patients). A total of 657 patients were treated with the ICS and 726 were treated with single screw nails. The combined pooled results showed that ICS significantly reduced the risk of revisions by $65 \%$ compared to single nails OR: $0.35,95 \%$ CI 0.20 to $0.60, I^{2}=$ $11 \%, \mathrm{p}<0.0001$. The results remained statistically significant for SHB $\mathrm{p}=0.0001$ when the single nails where considered individually and no difference was observed when ICS was compared with SLS alone $\mathrm{p}=0.48$ as shown in (Figure $3 \mathrm{~A}$ ).

Non-unions: Four studies reported data on non-union $[22,27,28,32](\mathrm{n}=811$ patients). A total of 364 patients were treated with the ICS and 447 were treated with single screw nails. The combined pooled results showed that overall, there was no statistical difference between ICS and the single screw nails in reducing the incidence of non-unions. The pooled results did not reach statistical significance with wide confidence intervals OR: $0.54,95 \%$ CI 0.17 to $1.66, I^{2}=0 \%$, $\mathrm{p}=0.28$ see (Figure $3 \mathrm{~B}$ ). Similar results were observed when SHB and SLS were considered individually.

\section{Patient related functional outcomes}

Harris Hip Score: All studies reported data on HHS [21-32] ( $n=1661$ patients). A total of 784 patients were treated with the ICS and 877 were treated with single screw nails. The combined pooled results showed that ICS significantly improved the HSS compared to single screw nails MD: $1.42,95 \%$ CI 0.23 to $2.61, I^{2}=51 \%, p=0.02$. The results remained significant for SHB $\mathrm{p}=0.03$ when the single screw nails where considered individually and no difference was observed when ICS was compared with SLS alone $\mathrm{p}=0.17$ as shown in (Figure $4 \mathrm{~A}$ ).

Hip and thigh pain: Eight studies reported data on the proportion of patients who complained of hip and thigh pain [21,25-28,31,32] $(\mathrm{n}=1323$ patients). A total of 620 patients were treated with the ICS and 703 were treated with single screw nails. The combined pooled results showed that ICS treated patients experienced significantly less complaints of hip and thigh pain ( $45 \%$ less people) compared to single screw nails OR: $0.55,95 \%$ CI 0.38 to $0.78, I^{2}=0 \%, p=0.0009$. The results

Table 2. Characteristics of included studies in the systematic review and meta-analysis.

\begin{tabular}{|c|c|c|c|c|}
\hline Study author \& year & Type of study \& Sample size & Mean age in years (Range) & Percentage of males & $\begin{array}{l}\text { Length of follow up, } \\
\text { months }\end{array}$ \\
\hline Seyhan [21] & RCT N=75: ICS=32; $\mathrm{SHB}=43$ & $\mathrm{ICS}=75.3(61.8-88.9) \mathrm{SHB}=75.9(62.2-89.6)$ & $\mathrm{ICS}=34.4 \mathrm{SHB}=18.6$ & 24 \\
\hline Zhang [22] & RCT N=113: ICS=47; SHB=46 & $\mathrm{ICS}=72.4(64.8-80.0)$ SHB-II $=72.4(63.7-81.1)$ & $\mathrm{ICS}=40.4 \mathrm{SHB}=33.9$ & 12 \\
\hline Gavaskar [23] & Observational $\mathrm{N}=100$ : $\mathrm{ICS}=50 ; \mathrm{SHB}=50$ & $\mathrm{ICS}=77 \pm 7 \mathrm{SHB}=78 \pm 8$ & $\mathrm{ICS}=21.9 \mathrm{SHB}=21.9$ & 12 \\
\hline Wang [24] & Observational $\mathrm{N}=56$ : $\mathrm{ICS}=20 ; \mathrm{SHB}=36$ & $\mathrm{ICS}=73.5 \mathrm{SHB}=76.8$ & $\mathrm{ICS}=55 \mathrm{SHB}=47.2$ & 4.6 \\
\hline $\mathrm{Yu}[25]$ & Observational $\mathrm{N}=168 ; \mathrm{ICS}=75 ; \mathrm{SHB}=72$ & $\mathrm{ICS}=75.2(66.4-84.0) \mathrm{SHB}=74.2(65.1-83.3)$ & $\mathrm{ICS}=35 \mathrm{SHB}=32$ & 12 \\
\hline Zehir [26] & Observational N=195; ICS $=102 ; \mathrm{SHB}=93$ & ICS $=76.9(70.2-83.6) \mathrm{SHB}=77.2(70.4-84.0)$ & ICS $=38.2 \mathrm{SHB}=38.5$ & 16 \\
\hline Zhang [27] & Observational N=174; ICS $=86 ; \mathrm{SHB}=88$ & ICS $=72.7(7.6) \mathrm{SHB}=74.6(6.3)$ & $\mathrm{ICS}=34.8 \mathrm{SHB}=38.6$ & 40 \\
\hline Zhang [28] & Observational $\mathrm{N}=283 ; \mathrm{ICS}=144 ; \mathrm{SHB}=139$ & ICS $=76.1 \mathrm{SHB}=76.1$ & $\mathrm{ICS}=56 \mathrm{SHB}=62$ & 38.8 \\
\hline Berger-Groch [29] & RCT N=104; ICS=55; SLS=49 & $\mathrm{ICS}=81.6(72.2-91.0) \mathrm{SLS}=82.0(72.8-91.2)$ & $\mathrm{ICS}=21.8 \mathrm{SLS}=24.5$ & 60 \\
\hline Hopp [30] & RCT N=78; ICS=39; SLS=39 & ICS $=82.7 \mathrm{SLS}=80.7$ years & $\mathrm{ICS}=18 \mathrm{SLS}=33.3$ & 12 \\
\hline $\mathrm{Su}[31]$ & RCT N=100; ICS=50; SLS=50 & $\mathrm{ICS}=70.1 \mathrm{SLS}=71.3$ & $\mathrm{ICS}=42.0 \mathrm{SLS}=38.0$ & 12 \\
\hline $\mathrm{Wu}[32]$ & Observational N=261; ICS $=87$; SLS $=174$ & $\mathrm{ICS}=71.4(61.7-81.1) \mathrm{SLS}=72.6(64.0-81.2)$ & $\mathrm{ICS}=23.0 \mathrm{SLS}=24.7$ & 12 \\
\hline
\end{tabular}


Nherera LM (2018) A meta-analysis of integrated compression screw compared to single screw nails using a single lag screw or single helical blade screw for intertrochanteric hip fractures

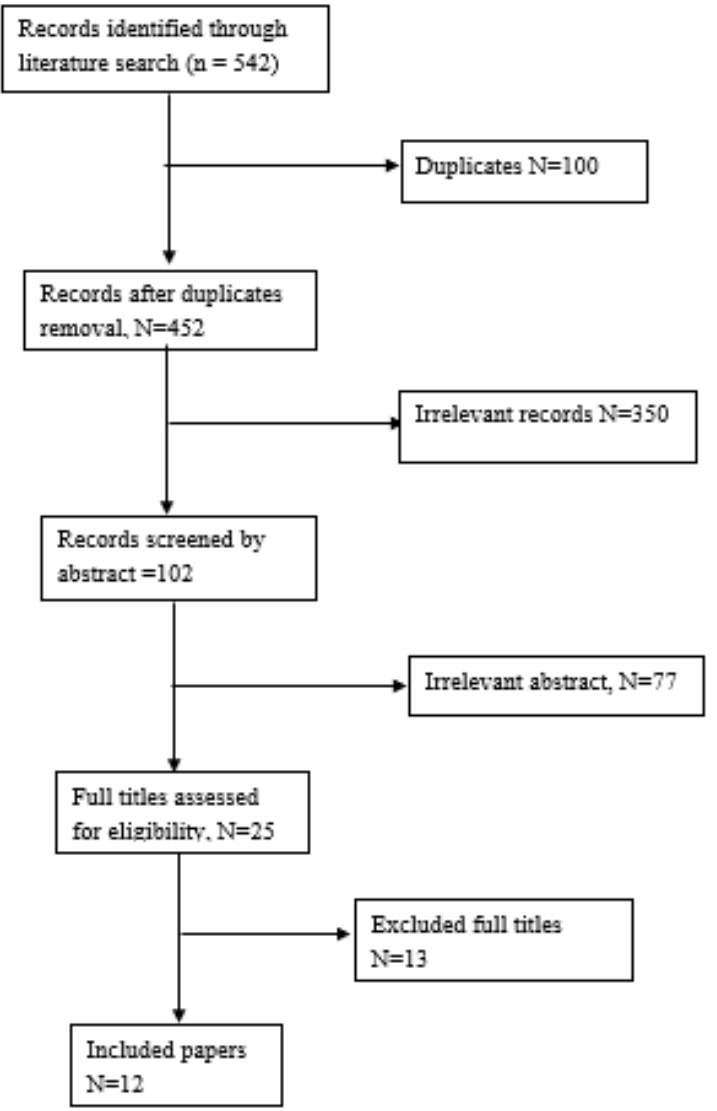

Figure 1. PRISMA flow diagram

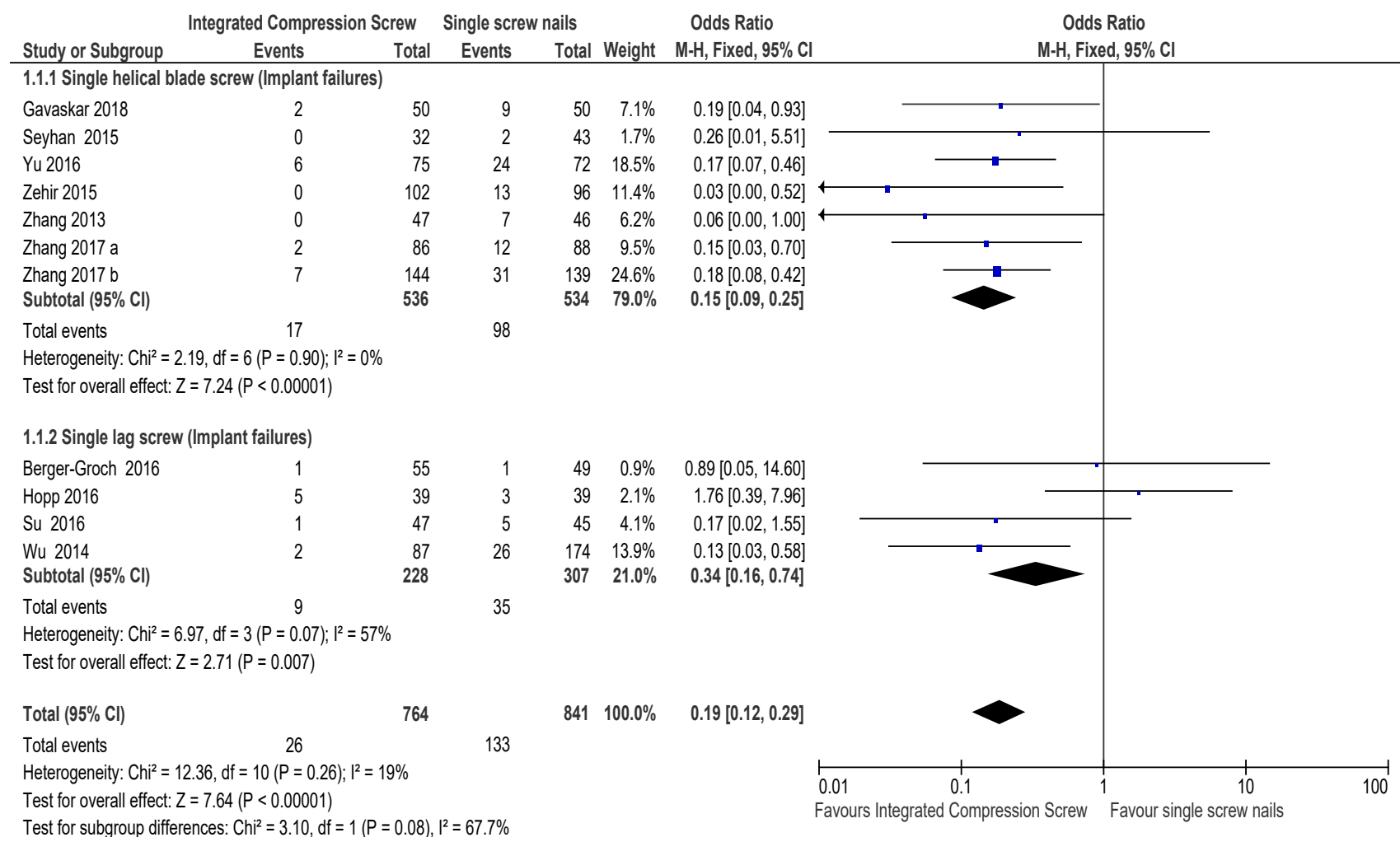

Figure 2. Impact of Integrated compression screw nail compared with single lag screws (a single lag screw or a single helical blade) on implant related failures defined as cut out, shaft fractures, varus collapse 
Nherera LM (2018) A meta-analysis of integrated compression screw compared to single screw nails using a single lag screw or single helical blade screw for intertrochanteric hip fractures

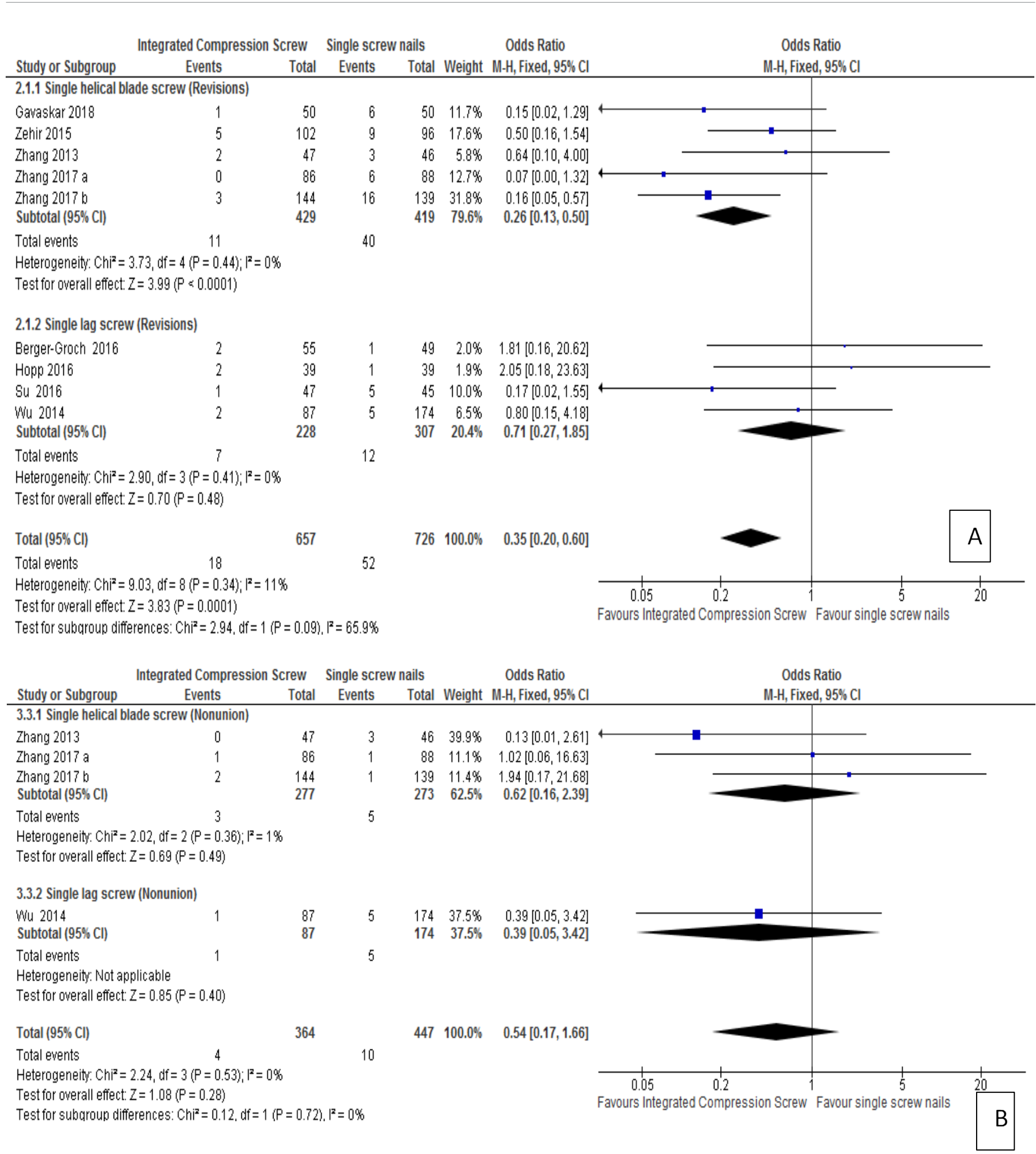

Figure 3. Impact of Integrated compression screw nail compared with single lag screws (a single lag screw or a single helical blade) on (A) Revisions and (B) Non-unions.

remained significant for SHB $\mathrm{p}=0.0005$ when the single screw nails where considered individually and no difference was observed when ICS was compared with SLS alone $\mathrm{p}=0.9$ as shown in (Figure $4 \mathrm{~B}$ ).

\section{Health related quality of life (Short form 36 physical function)}

Only one study reported health related quality of life outcomes [29] and had 104 patients in total. Overall, there was a statistically significant difference between ICS and SLS for this outcome in favour of ICS, the mean difference MD: $7.40,95 \%$ CI 2.73 to $12.07, p=0.002$ see (Figure 4C).

\section{Intra operative outcomes}

Operating time: Ten studies reported data on surgery time [21,22,24-27,29-32] ( $\mathrm{n}=1387$ patients). A total of 648 patients were 
Nherera LM (2018) A meta-analysis of integrated compression screw compared to single screw nails using a single lag screw or single helical blade screw for intertrochanteric hip fractures

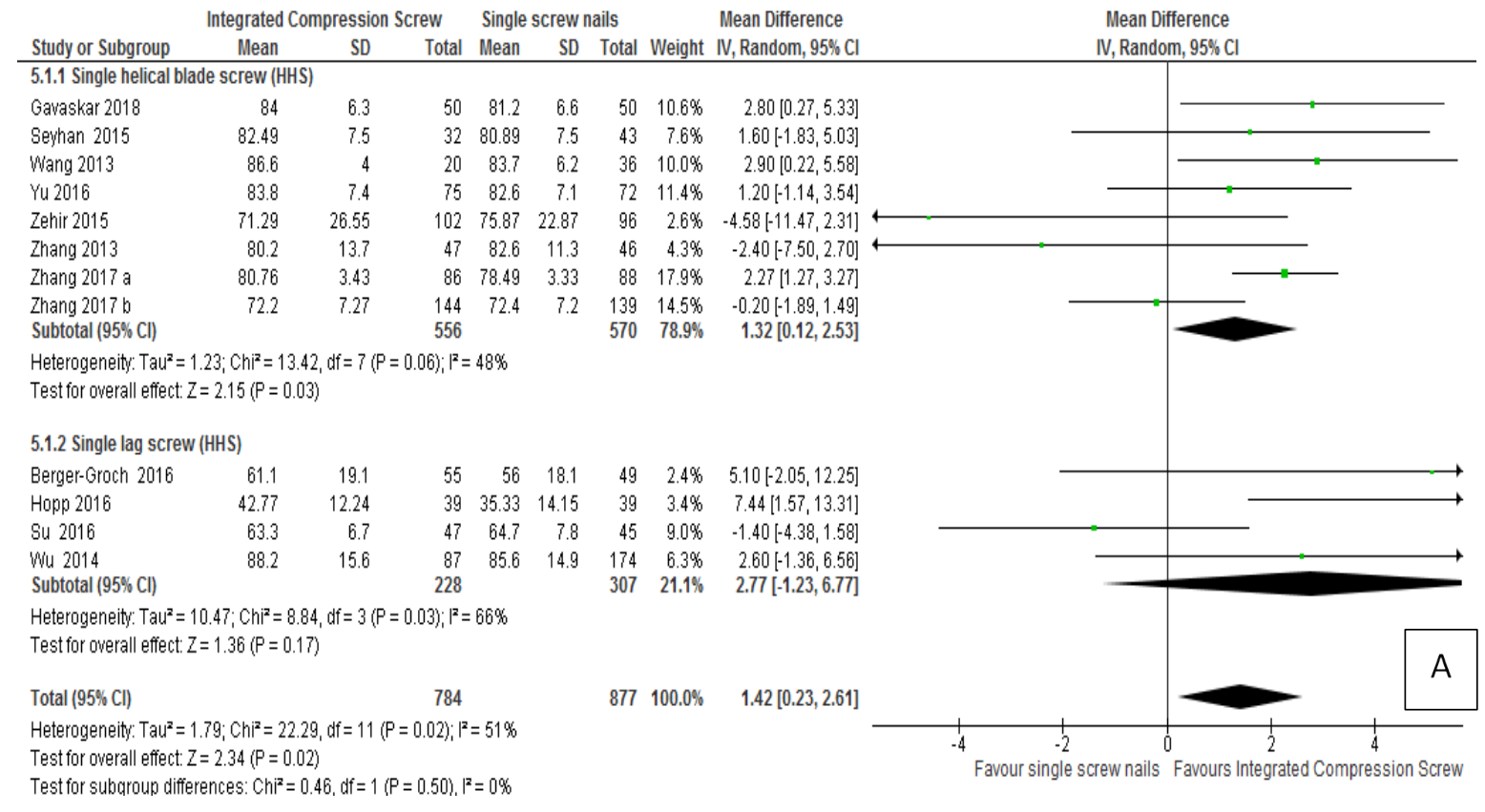

Integrated Compression Screw Single screw nails Odds Ratio Odds Ratio

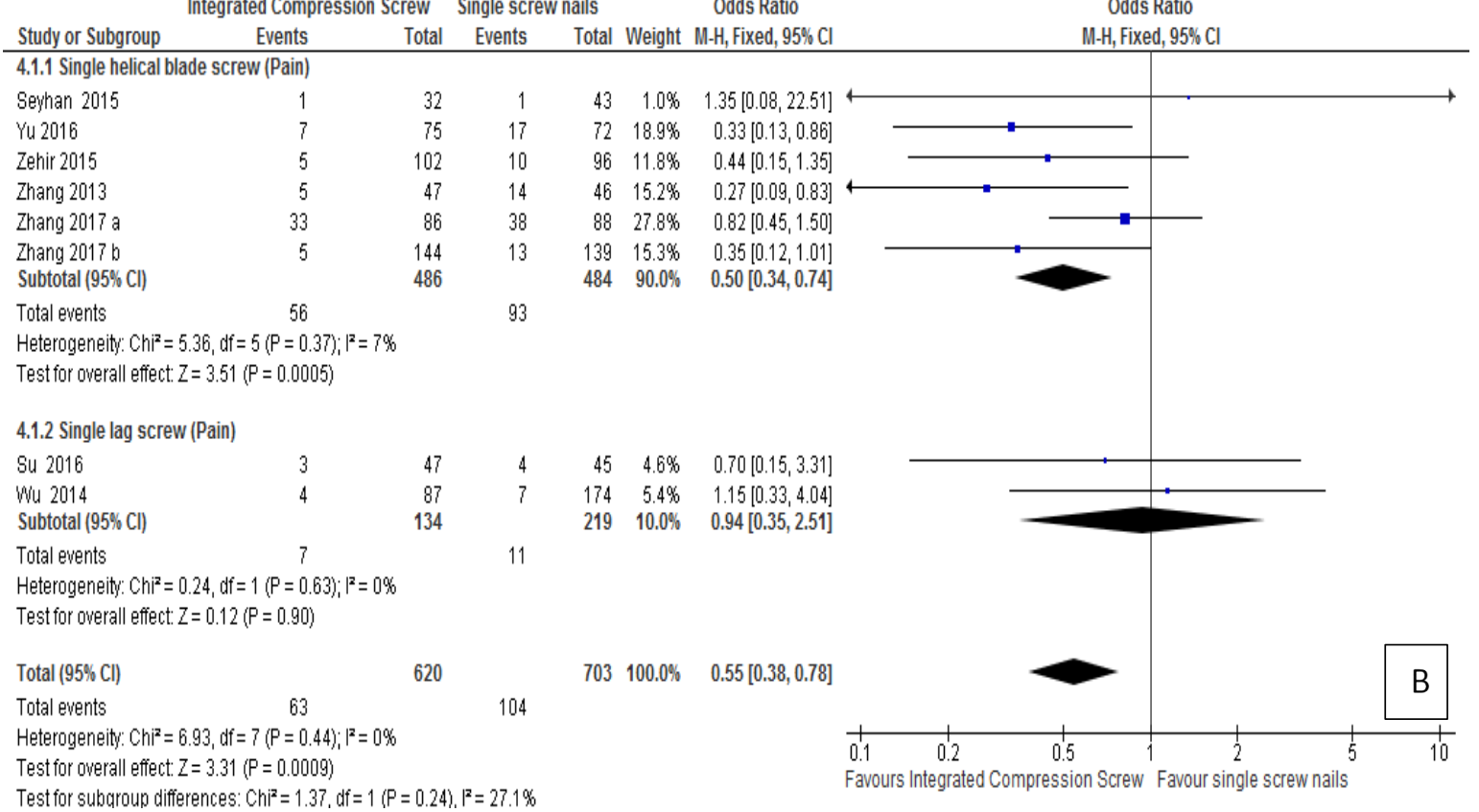

Test for subqroup differences: $\mathrm{Ch}^{2}=1.37, \mathrm{df}=1(\mathrm{P}=0.24), \mathrm{I}^{2}=27.1 \%$

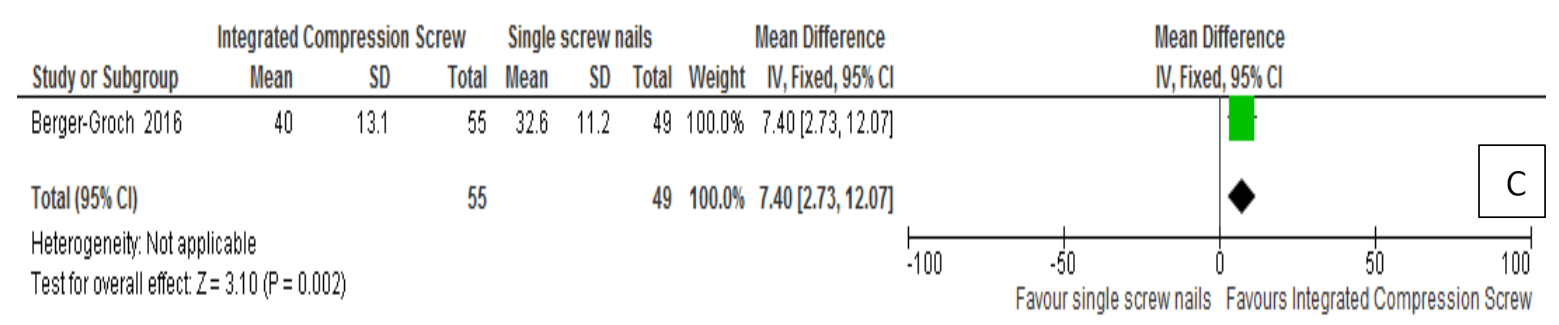

Figure 4. Impact of Integrated compression screw nail compared with single lag screws (a single lag screw or a single helical blade) on (A) Harris Hip Score, (B) Hip and thigh pain and (C) Physical component of the SF-36. 
Nherera LM (2018) A meta-analysis of integrated compression screw compared to single screw nails using a single lag screw or single helical blade screw for intertrochanteric hip fractures

treated with ICS and 739 were treated with single screw nails. The pooled results showed that ICS was associated with a marginally longer surgery time (+7.32 minutes) compared to single screw nails MD: 7.32, $95 \%$ CI 1.00 to $13.64, I^{2}=98 \%, p=0.02$. There were no differences seen when single screw nails were considered individually for SHB $\mathrm{p}=0.09$ and SLS alone $\mathrm{p}=0.07$ as shown in (Figure 5A).

Fluoroscopy time: Five studies reported data on fluoroscopy time $[22,25,26,30,32](n=777$ patients). A total of 350 patients were treated with ICS and 427 were treated with single screw nails. The combined pooled results showed that ICS was associated with extended fluoroscopy time $(+1$ minute) compared to single screw nails. $\mathrm{MD}$ : $1.00,95 \%$ CI 0.31 to $1.68, I^{2}=0 \%, p=0.004$. The results remained significant for SHB $\mathrm{p}=0.02$ and SLS $\mathrm{p}<0.00001$ when the single screw nails where considered individually as shown in (Figure 5B).

\section{Blood loss}

Eight studies reported data on the the amount of blood loss during surgery [22,24-26,28,30-32] ( $\mathrm{n}=1216$ patients). A total of 564 patients were treated with ICS and 652 were treated with single screw nails. The combined pooled results showed that there was no significant difference in the amount of blood loss between patients treated with ICS and single screw nails, MD: $6.40,95 \%$ CI -7.07 to $19.88, I^{2}=98 \%$, $\mathrm{p}=0.35$. The results were different when ICS was compared with SHB $p=0.03$, in favour of SHB, while no differences were observed when ICS was compared with SLS alone $\mathrm{p}=0.35$ although less blood loss was observed for ICS as shown in (Figure 5C).

\section{Other complications}

Six studies reported data on other complications. [21,22,28,3032] ( $n=903$ patients). A total of 399 patients were treated with ICS and 504 were treated with single screw nails. Other complications considered in this study were deep vein thrombosis, cardiovascular disorders, pressure sores, urinary tract infection, pulmonary embolism and hematomas. The combined pooled results showed that there was no difference in the incidence of other complications between ICS compared to single screw nails OR: $0.99,95 \%$ CI 0.65 to $1.49, I^{2}=0 \%$, $\mathrm{p}=0.94$. This result was maintained when the single screw nails where considered individually SHB $\mathrm{p}=0.85$ and SLS $\mathrm{p}=0.95$ as shown in (Figure 5D).

\section{Publication bias}

A funnel plot demonstrated no visual evidence of publication bias (Figure 6) for the primary outcome. Similar results were obtained for other outcomes. The outer dashed lines indicate the triangular region within which $95 \%$ of studies are expected to lie in the absence of both biases and heterogeneity.

\section{Sensitivity analysis}

The sensitivity analyses using alternative analysis methods (Peto method vs. Mantel-Haenszel method), and considerations of heterogeneity (random-effects vs. fixed-effect) did not show important changes in the pooled effects for these outcomes. One study had a follow up of less than 12 months [23] and contributed data on revisions and HHS outcomes. When this study was removed from the analysis, the overall conclusions remained the same.

We also assessed the impact of removing studies which had mixed populations. Four studies included patients with stable fractures OA/ OTA AI $[21,24,28,29]$. The proportion of patients with A1 was $8 \%$ i.e, 140 patients of the 1,661 total patients in the meta-analysis. When these studies were removed from the analysis to assess the effect of the implants on unstable patient only, the treatment effect slightly improved in favour of ICS for the primary outcome, i.e, reduction in implant related failures increased from $81 \%$ to $82 \% \mathrm{p}<0.00001$.

\section{Discussion}

Our study was conducted to explore whether integrated compression screw intramedullary nail provided better clinical outcomes compared to the single screw nailing system in unstable intertrochanteric fractures. Our pooled data showed that ICS provides more reliable fixation than single screw nail devices in this patient population. In particular the implant related fixation failure rate was reduced by $81 \%$ while revision rates were reduced by $65 \%$ the ICS group compared with the single screw nail fixation. We cannot be certain if all of the varus collapse reported in the studies were clinically relevant leading to revisions or they were simply varus progression of the neck or screw migration seen on the X-ray. Therefore, the reduction seen for implant failure needs to be interpreted with caution. Patients in the ICS group reported improvement in quality of life as measured by the physical component of the SF-36 and fewer people complained of hip and thigh pain. Significantly the HHS was improved overall in patients treated with ICS. These findings suggest that there is unlikely to be a class effect of intramedullary nails for the treatment of unstable intertrochanteric fractures.

Statistically significant differences in favour of single screw devices regarding surgery time (-7 minutes faster) and fluoroscopy time (-1 minute) were identified, although the absolute change in time, within the context of the surgical procedure, was considered marginal. Our study did not find any difference in non-union rates, blood loss or other complications such as deep vein thrombosis, cardiovascular disorders, pressure sores, urinary tract infection, pulmonary embolism and hematomas.

Previous studies have noted that quality of life and functional status following surgery are of particular importance. HHS is used to evaluate the results of hip surgery and the score can comprehensively assess the function of the patient after hip surgery. Our meta-analysis showed that ICS significantly improved postoperative functional recovery as well as reducing hip and thigh pain. Yu [25], observed that long-term pain arises due to implant failures and in line with the proposed association between implant failure and long term pain our study demonstrated that, the use of ICS resulted in a significant reduction in implant related failures and reduced hip and thigh pain. We appreciate that a direct causal relationship cannot be established from our analysis, however we believe it adds further weight to the conclusion by $\mathrm{Yu}$ [25]. There was a relative paucity of data on quality of life in the studies, with only one study reporting relevant data [29]. Whilst there is a plausible hypothesis that improvements in pain, revisions and implant failures is likely to result in improved QoL, further data on this outcome would be desirable.

Surgery and fluoroscopy time favoured single screw nails. This finding is in line with other previous analyses which found that ICS requires more time [13-15]. The causes of the difference in operating time are not clearly understood although it is speculated that the shape of ICS device may contribute to this. As in previous studies [13], the differences in operating time ( 7 minutes) are considered marginal when considered in the context of the entire procedure. Similarly, although no difference was observed regarding blood loss, there was a marginal increase in blood loss for ICS treated patients $(6 \mathrm{~mL})$. The difference in blood loss is most likely attributable to the longer surgical 
Nherera LM (2018) A meta-analysis of integrated compression screw compared to single screw nails using a single lag screw or single helical blade screw for intertrochanteric hip fractures

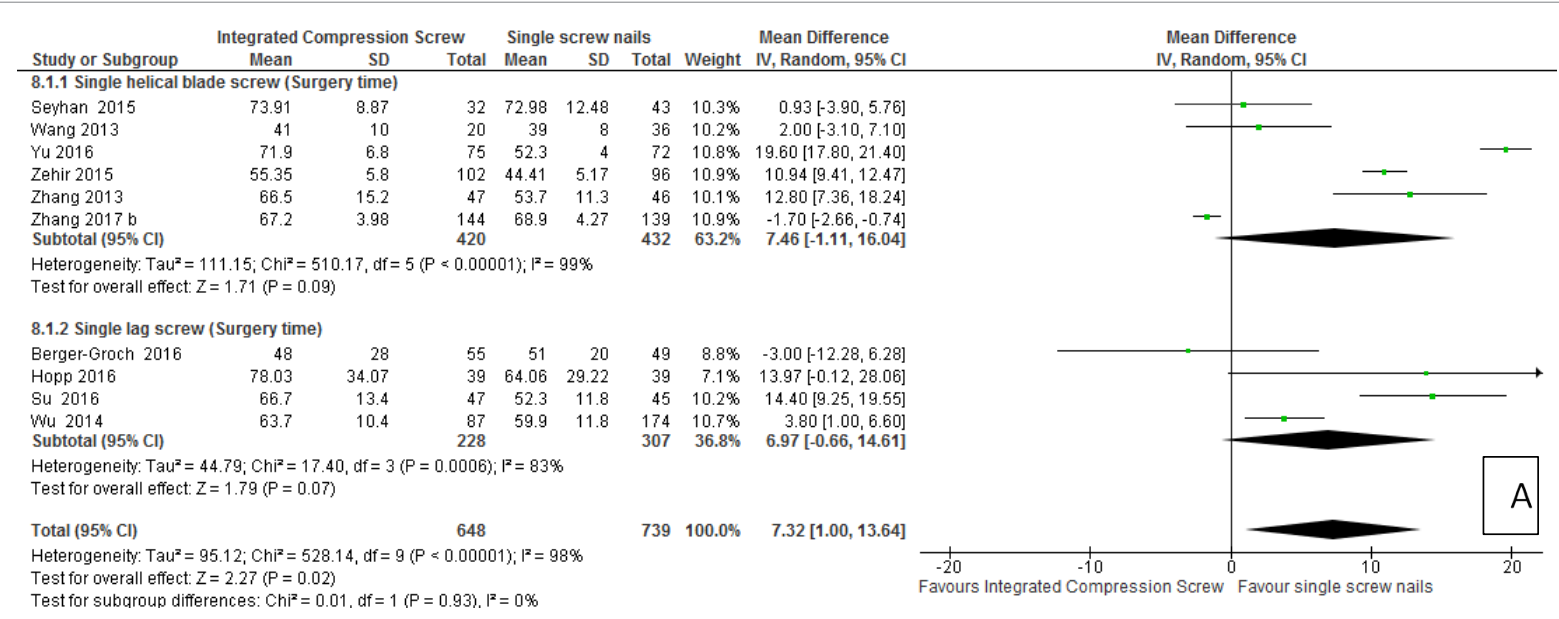

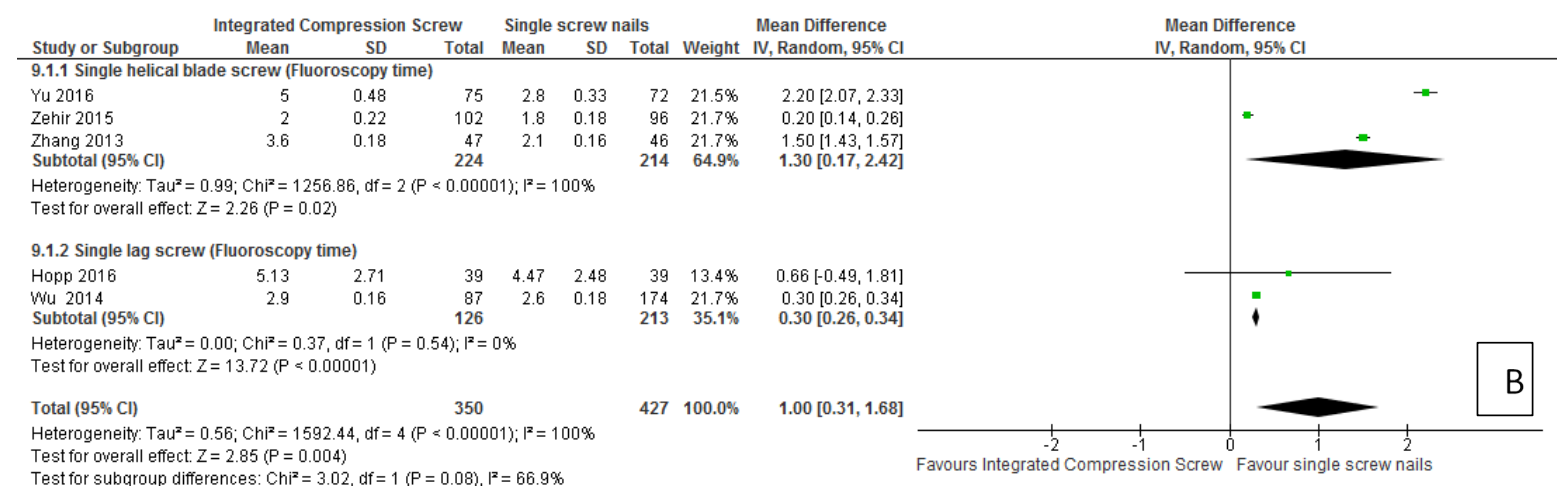

Test for subaroup differences: $\mathrm{Chi}^{2}=3.02, \mathrm{df}=1(\mathrm{P}=0.08), \mathrm{I}^{2}=66.9 \%$

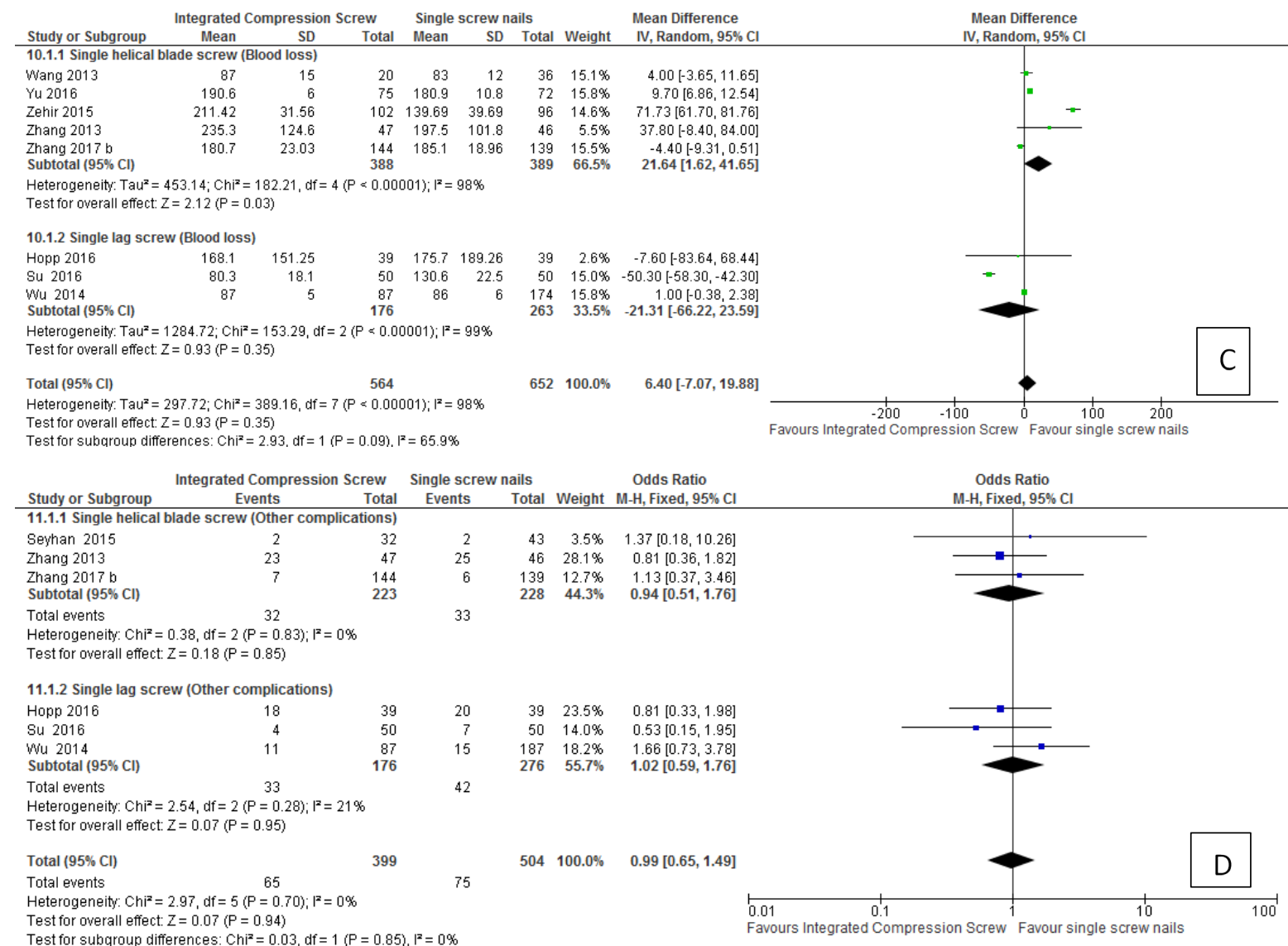

Figure 5. Impact of Integrated compression screw nail compared with single lag screws (a single lag screw or a single helical blade) on (A) operating time, (B) fluoroscopy time, (C) blood loss and (D) Other complications. 


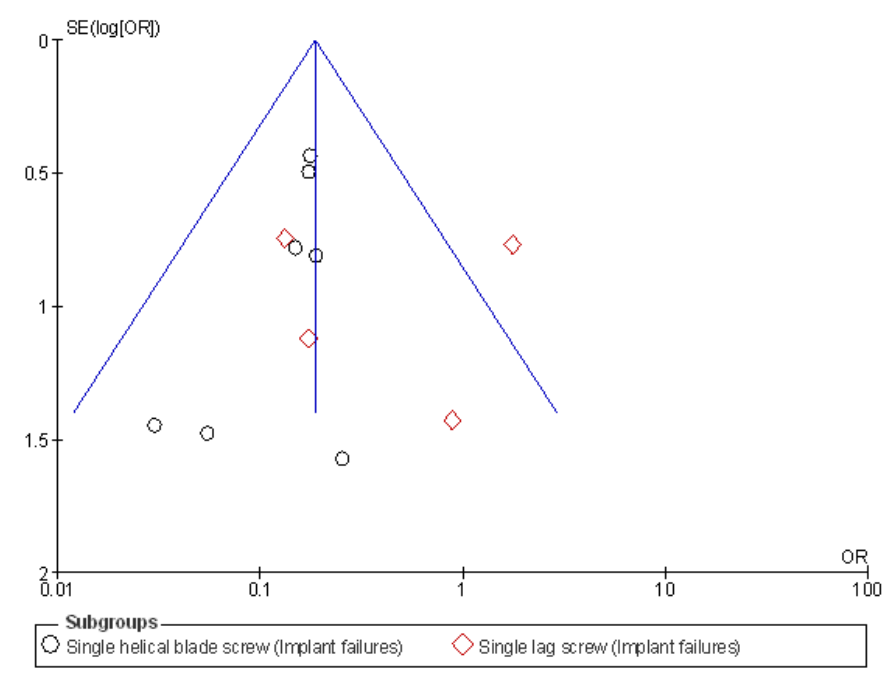

Figure 6. Funnel plot for the meta-analysis of the Integrated compression screw nail compared to single screws nails (a single lag screw or a single helical blade). (The forest plots show the odds ratio (OR) calculated by the random effects model or the mean difference (MD) calculated by the fixed effects model. Squares represent individual study effects and diamonds represent the summary effect from the meta-analysis. Horizontal bars represent $95 \% \mathrm{CIs}$ and the vertical line in plot is at 1 for $\mathrm{OR}$ and 0 for $\mathrm{MD}$, corresponding to the null hypothesis of no effect. $\mathrm{I}^{2}=$ test of heterogeneity, CI, confidence interval; df, degree of freedom; M-H, Mantel-Haenszel).

time associated with ICS nails as was reported by Su (2016) [31]. The procedure results differed according to the type of single screw nail used, for instance there was more operating time in ICS nails when compared to SHB and less time when compared to SLS. We suspect that the presence of the varying procedural outcomes between studies may also result from different levels of expertise/experience among the surgeons participating in those studies.

We conducted a comprehensive systematic review and metaanalysis using rigorous methods using all available published comparative evidence i.e. both RCT and observational evidence. A total of 12 studies were included in the analysis with 1661 patients treated with either ICS nails (784) or single screw nails (877). This gives a sample size which is large enough to draw meaningful conclusions about the performance of the nails under consideration. Also, by considering all published comparative evidence, we were able to utilise the advantages of each type of study design i.e., RCTs providing internal validity and efficacy information while observational studies provide external validity and effectiveness information of the intervention [13]. Although our analysis reported the combined results of both single screw nails, we were also able to consider the single screw nails individually. We noted that all the single screw nails were in agreement with regards to the primary outcome of implant related failures and that there was further agreement with regards to HHS. There was divergence for instance with regards to revision and pain where there was significant reduction when ICS nails was compared to SHB and no difference when compared with SLS. These outcomes may be attributable in part to differences in the volume of data considered in the analysis, i.e. there were 8 studies included for SHB and 4 studies for SLS.

There are some limitations in our systematic review and metaanalysis. Firstly, 5 of the 12 studies included in the analysis were RCTs and the rest (7) were observational studies. The sample sizes of the RCTs ranged from 75 to 113 while observational studies ranged from 56 to 283 . The results may have been driven by the less wellcontrolled observational studies which contributed more patients in the analysis. However, we assessed the possibility of publication bias using the funnel plots. The funnel plot did not suggest asymmetry because the estimated effects are scattered within the superimposed limits. Assessment of publication bias is often difficult if the number of studies is not large $(<10)$ [20], however since we had more than 10 studies in our meta-analysis we are confident with the no bias finding of our analysis. Secondly, the follow-up of patients is different between the included articles. One study conducted by Wang [24] reported the mean time of follow up is 4.6 months while the majority of studies reported 12 months or over. This study only reported on two outcomes (HHS and surgery time). Removing the study from the analysis did not change the overall findings. Thirdly, we noted there was variation in procedure outcomes, mainly surgery and fluoroscopy time. For instance the difference between the shortest, 41 minutes in the study by Wang [24], and longest surgery time, 78 minutes in the study by Hopp [30], was 37 minutes. Such heterogeneity may be indicative of different levels of surgical experience and may may affect the results of metaanalysis. However, we accept that such differences between studies are inevitable and are experience dependant. Finally, we would have preferred to have results reported by fracture type for those studies that included mixed populations of stable and unstable fractures, but this was not always reported. We are still nonetheless confident that the results are representative of unstable fractures as $95 \%$ of the patients included in the analysis had unstable fractures and furthermore removing the studies with mixed populations had little impact on the overall conclusions of the meta-analysis.

\section{Conclusion}

The current body of evidence suggests that ICS nails may offer improved outcomes in terms of implant related complications, revision rates and better functional outcomes, including reduced pain, when compared to single screw nails. Procedure related outcomes, such as surgery time, tend to favour the single screw nails compared to ICS nails. We noted there was no difference between ICS compared to single screw nails with regards to blood loss, non-unions and other complications. There is a need for further studies especially between ICS nails and SLS and further evidence on quality of life would also be beneficial. Given the superiority of ICS for the major outcomes in patients with intertrochanteric fractures, clinicians and policy makers should be encouraged to implement protocols that incorporate appropriate use of ICS nails in order to maximise health benefits to the patients and bring value to the payers. This evidence has led to the rejection of the notion that there could be a class effect of intramedullary nails for unstable fractures.

\section{Authorship}

LN Conducted the meta-analysis and interpretation of results including the writing of the manuscript, PT, AH, AJJ, JTW contributed to the interpretation of results and commenting on the manuscript.

\section{Acknowledgements}

\section{None}

\section{Funding}

There is no funding source

\section{Competing interest}

LN, PT \& AH are employees of Smith \& Nephew the manufacturer of InterTAN. AJJ \& JTW have no competing interests. 
Nherera LM (2018) A meta-analysis of integrated compression screw compared to single screw nails using a single lag screw or single helical blade screw for intertrochanteric hip fractures

\section{Ethical approval}

Not applicable as this article does not contain any studies with human participants or animals that were performed by any of the authors.

\section{Informed consent}

Not applicable, as the study is a secondary analysis of data.

\section{References}

1. Ruecker AH, Rupprecht M, Gruber M, Gebauer M, Barvencik F, et al. (2009) The treatment of intertrochanteric fractures: results using an intramedullary nail with integrated cephalocervical screws and linear compression. J Orthop Trauma 23: 22-30. [Crossref]

2. Mundi S, Pindiprolu B, Simunovic N, Bhandari M (2014) Similar mortality rates in hip fracture patients over the past 31 years. Acta Orthop 85: 54-59. [Crossref]

3. De Laet CE, van Hout BA, Burger H, Hofman A, Pols HA (1997) Bone density and risk of hip fracture in men and women: cross sectional analysis. BMJ 315: 221-225. [Crossref]

4. Swart E, Makhni EC, Macaulay W, Rosenwasser MP, Bozic KJ (2014) Costeffectiveness analysis of fixation options for intertrochanteric hip fractures. $J$ Bone Joint Surg Am 96: 1612-1620. [Crossref]

5. Burge R, Dawson-Hughes B, Solomon DH, Wong JB, King A, et al. (2007) Incidence and economic burden of osteoporosis-related fractures in the United States, 2005-2025. J Bone Miner Res 22: 465-475. [Crossref]

6. Søgaard AJ, Holvik K, Meyer HE, Tell GS, et al. (2016) Continued decline in hip fracture incidence in Norway: a NOREPOS study. Osteoporos Int 27: 2217-2222. [Crossref]

7. Nieves JW, Bilezikian JP, Lane JM, Einhorn TA, Wang Y, et al. (2010) Fragility fractures of the hip and femur: incidence and patient characteristics. Osteoporos Int 21: 399-408.

8. Leal J, Gray AM, Prieto-Alhambra D, Arden NK, Cooper C, et al. (2016) Impact of hip fracture on hospital care costs: a population-based study. The REFReSH study group. Osteoporos Int 27: 547-558.

9. Klop C, Welsing PM, Cooper C, Harvey NC, Elders PJ, et al (2014) Mortality in british hip fracture patients, 2000-2010: A population-based retrospective cohort study. Bone 66: 171-177.

10. Imai N, Endo N, Hoshino T, Suda K, Miyasaka D, et al (2016) Mortality after hip fracture with vertebral compression fracture is poor. J Bone Miner Metab 34: 51-54.

11. Yu J, Zhang C, Li L, Kwong JSW, Xue L, et al (2015) Internal fixation treatments for intertrochanteric fracture: a systematic review and meta-analysis of randomized evidence. Sci Rep 5: 18195.

12. Kaplan K, Miyamoto R, Levine BR, Egol KA, Zuckerman JD (2008) Surgical management of hip fractures: an evidence-based review of the literature. II: intertrochanteric fractures. J Am Acad Orthop Surg 16: 665-673.

13. Nherera L, Trueman P, Horner A, Watson TJ, Johnstone AJ (2018) Comparison of a twin interlocking derotation and compression screw cephalomedullary nail (InterTAN) with a single screw derotation cephalomedullary nail (proximal femoral nail antirotation): a systematic review and meta-analysis for intertrochanteric fractures. J Orthop Surg Res 13: 46

14. Ma J, Kuang M, Fan Z, Xing F, Zhao Y, et al. (2017) Comparison of clinical outcomes with InterTan vs Gamma nail or PFNA in the treatment of intertrochanteric fractures: A meta-analysis. Sci Rep 7: 1.
15. Liu P, Wu X, Shi H, Liu R, Shu H, et al. (2015) Intramedullary versus extramedullary fixation in the management of subtrochanteric femur fractures: a meta-analysis. Clin Interv Aging pp. 803-811.

16. Shamseer L, Moher D, Clarke M, Ghersi D, Liberati A, et al. (2015) Preferred reporting items for systematic review and meta-analysis protocols (PRISMA-P) 2015 elaboration and explanation. BMJ 349: 7647.

17. Higgins JP, Altman DG, Gøtzsche PC, Jüni P, Moher D, et al. (2011) The Cochrane Collaboration's tool for assessing risk of bias in randomised trials. BMJ 343: d5928. [Crossref]

18. Dreyer NA, Velentgas P, Westrich K, Dubois R (2014) The GRACE checklist for rating the quality of observational studies of comparative effectiveness: a tale of hope and caution. J Manag Care Spec Pharm 20: 301-308.

19. Higgins JP, Thompson SG (2002) Quantifying heterogeneity in a meta-analysis. Stat Med 21: 1539-1558. [Crossref]

20. Sedgwick P (2013) Meta-analyses: how to read a funnel plot. BMJ 346: 1342.

21. Seyhan M, Turkmen I, Unay K, Ozkut AT (2015) Do PFNA nails and Intertan nails both have the same effects in the treatment of trochanteric fractures? A prospective clinical study. J Orthop Sci 20:1053-1061.

22. Zhang S, Zhang K, Jia Y, Yu B, Feng W (2013) InterTan nail versus Proximal Femoral Nail Antirotation-Asia in the treatment of unstable trochanteric fractures. Orthopedics. 36: e288-294.

23. Gavaskar AS, Tummala NC, Srinivasan P, Gopalan H, Karthik B, et al. (2018) Helical blade or the integrated lag screws: A matched pair analysis of 100 patients with unstable trochanteric fractures. J Orthop Trauma 32: 274-277. [Crossref]

24. Wang YG, Chen M, Hu JK, Zhen WW, Ding XP (2013) Comparison of three fixations for treatment of intertrochanteric femoral fractures in the elderly. Zhongguo Gu Shang 26: 651-655. [Crossref]

25. Yu W, Zhang X, Zhu X, Hu J, Liu Y (2016) A retrospective analysis of the InterTan nail and proximal femoral nail anti-rotation-Asia in the treatment of unstable intertrochanteric femur fractures in the elderly. J Orthop Surg Res 11: 1.

26. Zehir S, Sahin E, Zehir R (2015) Comparison of clinical outcomes with three different intramedullary nailing nails in the treatment of unstable trochanteric fractures. Ulus Travma Acil Cerrahi Derg 21: 469-476.

27. Zhang H, Zeng X, Zhang N, Zeng D, Xu P, et al. (2017) INTERTAN nail versus proximal femoral nail antirotation-Asia for intertrochanteric femur fractures in elderly patients with primary osteoporosis. J Int Med Res 45: 1297-1309.

28. Zhang H, Zhu X, Pei G, Zeng X, Zhang N, et al. (2017) A retrospective analysis of the InterTan nail and proximal femoral nail anti-rotation in the treatment of intertrochanteric fractures in elderly patients with osteoporosis: a minimum follow-up of 3 years. Orthop Surg Res 12: 1 .

29. Berger-Groch J, Rupprecht M, Schoepper S, Schroeder M, Rueger JM, et al. (2016) Five-year outcome analysis of intertrochanteric femur fractures: A prospective randomized trial comparing a 2 -screw and a single-screw cephalomedullary nail. $J$ Orthop Trauma 30: 483-488.

30. Hopp S, Wirbel R, Ojodu I, Pizanis A, Pohlemann T, et al. (2016) Does the implan make the difference? - Prospective comparison of two different proximal femur nails. Acta Orthop Belg 82: 319-331.

31. Su H, Sun K, Wang X (2016) A randomized prospective comparison of Intertan and Gamma3 for treating unstable intertrochanteric fractures. Int J Clin Exp Med 9: 8640-8647.

32. Wu D, Ren G, Peng C, Zheng X, Mao F, et al. (2014) InterTan nail versus Gamma3 nail for intramedullary nailing of unstable trochanteric fractures. Diagn Pathol 9: 1.

Copyright: ( 2018 Nherera LM. This is an open-access article distributed under the terms of the Creative Commons Attribution License, which permits unrestricted use, distribution, and reproduction in any medium, provided the original author and source are credited. 